\title{
As Constituições da Era Vargas: uma abordagem à luz do pensamento autoritário dos anos $\mathbf{3 0}$
}

Fernanda Xavier da Silva *

\section{Resumo}

O presente trabalho procura analisar as Constituições de 1934 e 1937 a partir da influência exercida pela corrente brasileira de pensamento autoritário; única portadora de uma efetiva ideologia de Estado no período. Tendo em vista o papel desempenhado pelas Constituições na sociedade moderna (construção do moderno Estado de direito e expressão da vontade do povo), associado àquele the imposto pelo contexto nacional (refundação do Estado), o estudo dessas duas Cartas visa confirmar o protagonismo político assumido por essa corrente de pensamento, destacando, ainda, as ambiguiidades desses textos. Para tal, analisamos minuciosamente ambas as Constituições traçando um paralelo, ao mesmo tempo, com os temas e categorias da ideologia de Estado do que denominamos Pensamento Autoritário Brasileiro (PAB) e com as Cartas de 1891 e 1946. Procuramos, desta forma, revelar a essência dessas Constituições analisando-as não como meros textos jurídicos, mas como legislações inseridas em um ambiente político-cultural específico.

Palavras-chave: Era Vargas, pensamento autoritário brasileiro, Constituições dos anos 30, Estado autoritário.

\section{Introdução}

A primeira metade do século XX caracterizou-se mundialmente Acomo um período de ampla instabilidade econômica, social e política; momento de eclosão das duas guerras mundiais associado

Mestre em Ciências Sociais pela Universidade Federal de São Carlos; Doutoranda do Programa de Pós-Graduação em Sociologia da Universidade Estadual de Campinas (UNICAMP). Endereço eletrônico: fernanda.xav@hotmail.com. 
à maior crise econômica da história. Denominada Era da Catástrofe, assinalou uma conjuntura de grandes reavaliações e mudanças, quando o regime liberal entrou em colapso e três opções lutaram pela hegemonia intelectual política: 1) o comunismo; 2) o capitalismo reformado, associado com a social-democracia dos movimentos trabalhistas não comunistas; e 3) a direita, junto a qual se sobressaiu sua versão radical identificada no nazifascismo. Contrariando as expectativas que acreditavam que a depressão econômica pudesse abrir espaço para o avanço da esquerda, o início do século XX assinalou o refluxo da economia mundial e a ascensão dos nacionalismos radicais de direita responsáveis pela completa redefinição dos princípios norteadores do mundo (HOBSBAWN, 2003) ${ }^{1}$.

O Brasil, a reboque desse contexto, vivenciou uma grave crise econômica, política e social que teve como resultado a derrubada da Primeira República, e a posterior introdução da ditadura do Estado Novo. A despeito dessa semelhança, a crise brasileira foi menos um reflexo da crise internacional e mais um produto das condições vigentes internamente. Questionava-se, aí, a orientação agrárioexportadora de nossa economia, entendida como responsável pela manutenção da dependência externa e vulnerabilidade econômica do país; criticava-se o excesso de federalismo da Constituição de 1891, por permitir a prática de políticas particularistas que criavam e reproduziam um sistema social desigual; e, por último, assistia-se à formação de movimentos oposicionistas propondo a quebra do monopólio político das oligarquias e a incorporação das classes emergentes, uma vez que o crescimento das cidades e a diversificação da economia (sobretudo ante a crise de 1929) geraram novas forças sociais incompatíveis com a política vigente. Logo, o cenário mundial agiu apenas no sentido de tornar patente um problema já latente no país (FAUSTO, 2002).

Como no mundo, foi em torno dessas três alternativas que o pensamento brasileiro se estruturou. Encabeçando a posição de

1 Esse trabalho é parte da pesquisa realizada em meu mestrado junto ao Programa de Pós-Graduação em Ciências Sociais da Universidade Federal de São Carlos (UFSCar), sob orientação do Prof. Dr. Marco Antônio Villa e que contou com financiamento da Capes. 
esquerda tínhamos o PCB (Partido Comunista Brasileiro) e a ele diretamente relacionada a ANL (Aliança Nacional Libertadora) (GOMES VIANNA, 1990). Representando a via capitalista democrática destacavam-se alguns pensadores, como Nestor Duarte e Sérgio Buarque, mas ainda de pouca influência política (PIVA, 2000). Já na direita encontrávamos um amplo arranjo de ideias autoritárias composto por diversos autores e grupos com feições e projetos variados (exemplo o integralismo de Plínio Salgado e o pensamento católico de Tristão Athaíde), (BEIRED, 1999). Pelo número e grau de sistematização dessas ideias, aliado à inexistência de autêntica ideologia liberal e, em consequiência, ausência de antagonismos de classe necessários à organização do proletariado ${ }^{2}$, somados ao contexto mundial de refluxo do liberalismo, aqui também a direita foi a opção que obteve maior destaque.

Entre os anos de 1914 e 1945, o país assistiu a formação de uma nova direita nacionalista que, face ao contexto de crise vigente, desenvolveu uma inflexão do nacionalismo dotando-lhe de contornos autoritários. Segundo Beired (1999), esta direita se fez nova na medida em que representou uma ruptura com o padrão tradicional da direita: ao invés de advogar em favor do liberalismo, combateu-o fortemente, tendo o antiliberalismo como sua principal plataforma.

Isso se explica uma vez que seus membros identificavam os problemas nacionais como resultantes da incongruência das instituições liberais com a realidade nacional. Criticavam o utopismo das ideias iluministas, defendendo a substituição do liberalismo por uma autêntica ideologia nacional. Conforme Beired, "liberdade e igualdade eram tidas como abstrações a ser substituídas por outros valores políticos que privilegiassem a autoridade, a ordem, a hierarquia e a

2 Historicamente o liberalismo brasileiro foi abandonado em favor da manutenção da ordem. Isso não se fez diferente nos anos 30, quando, em face da radicalização e popularização dos movimentos políticos (cujas principais expressões foram a AIB e ANL) essa elite, supostamente liberal, abdicou do controle da direção política com vistas a conservar seu atual status-quo (CAMARGO, 1989). Já a embrionária esquerda brasileira, dado as suas deficiências formativas, optou por aliançar-se às forças antifascistas do que decorre o fracasso da Intentona Comunista de 1935 e a posterior dissolução do partido - sobreestimam poder do movimento, ao passo que se iludem quanto à tomada da consciência de classe por parte dos trabalhadores (DEL ROIO, 2002). 
obediência" (BEIRED, 1999, p.19). Como resultado, atuaram de forma incisiva na formulação de alternativas à ordem liberal-oligárquica.

É importante destacar que tal consenso de avaliação e objetivos, não significou a existência de um programa único por parte da direita. Suas propostas variaram de acordo com o diagnóstico da crise realizado por cada um de seus membros. De fato, é possível dividir essa direita em três pólos políticos intelectuais distintos, com base nos projetos que encabeçavam: um católico, um fascista e outro autoritário cientificista (BEIRED, 1999, p.14).

O primeiro polo, o católico, compreendia os intelectuais relacionados à revista católica $A$ Ordem e ao Centro Dom Vital. Tinham como tema central a reespiritualização da sociedade face ao materialismo e individualismo vigentes, buscando a rearticulação das relações entre Igreja e Estado - demanda, em parte, realizada pela Carta de 1934. Já o segundo, o pólo fascista, foi aquele que mais se aproximou do fascismo italiano. Teve no movimento integralista sua maior e quase que única expressão. Por fim, o pólo científico englobava o conjunto de intelectuais que apelava à ciência para a legitimação de suas ideias. Caracterizava-na, sobretudo a Sociologia, como veículo à compreensão objetiva da sociedade e consequiente desenvolvimento do país, a partir da elaboração de um novo instrumental de ação do governo. Congregando intelectuais de renome como Oliveira Vianna, Azevedo Amaral e Francisco Campos ${ }^{3}$, foi este último pólo o que maior obteve destaque no período (BEIRED, 1999).

Tal grupo exerceu grande influência junto à política nacional da década de 30 , chegando mesmo a determinar seus rumos. Alguns de seus membros participaram ativamente da elaboração do projeto constitucional de 1933, da reforma política e econômica varguista e, até mesmo, da política educacional dos anos 30. Conforme Fausto, "os principais ideólogos da corrente tiveram papel significativo na criação de instituições e na vida política em geral"

3 Ainda que possa parecer arbitrário pressupor unidade entre autores em parte díspares, assim o fazemos. Primeiramente, porque entendemos que seus projetos partilhavam de um mesmo objetivo imediato: o fortalecimento do poder na figura do Executivo. Em segundo lugar, por se tratar de uma classificação usual às obras que analisam o pensamento autoritário dos anos 30. (Ver LAMOUNIER. 1979; PIVA, 2000; FAUSTO, 2002; SILVA, 2004). 
(FAUSTO, 2001, p.20). Intitulando o trabalho intelectual a serviço da "descoberta das leis naturais que regiam o social, de modo a explicar e conduzir o desenvolvimento humano" atuaram como verdadeiros intelectuais do governo (BEIRED, 1999, p.23). Não bastasse, foi também este o grupo cuja elaboração de ideias teve um caráter mais propriamente ideológico no período.

Segundo Lamounier, esse grupo do pensamento autoritário, o $\mathrm{PAB}^{4}$, foi responsável pela elaboração de uma nova ideologia de natureza político-institucional: a ideologia do Estado Autoritário. Condensando a reação filosófica ao Iluminismo e ao utilitarismo, instrumentalizaram um novo modelo de administração política, centrado no fortalecimento do Executivo e legitimação da autoridade do Estado como princípio tutelar da sociedade (LAMOUNIER, $1979)^{5}$. Ao debater temas como crise, liberalismo, elitismo, nacionalismo, corporativismo e autoritarismo, esses autores procuraram deslegitimar o liberalismo e qualquer outro princípio a ele relacionando, apresentando, em seu lugar, o autoritarismo como um imperativo histórico ao povo brasileiro e, por isso, incontestavelmente legítimo - diante do caráter inorgânico da sociedade brasileira, fazia-se forçoso um Estado que a tutelasse; longe de representar uma ameaça às liberdades individuais, ele era, de fato, sua única garantia (VIANNA, 1939).

Ainda que aludissem à participação da sociedade a partir de sua organização em corporações, este corporativismo aparecia mais como um suporte teórico que amainava a construção do Estado autoritário no Brasil, do que como uma esfera real de representatividade - empregado em sua feição dirigista, caracterizava, antes, um dever social do indivíduo que seu direito (Rodrigues, 1990). Para o PAB, era a incapacidade em manter a ordem social, a ausência de

4 A partir de agora nos referiremos ao pólo cientificista do pensamento autoritário brasileiro através da sigla PAB (Pensamento Autoritário Brasileiro), visto que seus membros constituíram a face autoritária do período.

5 Partilhamos aqui da visão de Ricardo Silva que identifica este modelo de interpretação como o mais adequado ao estudo do pensamento autoritário dos anos 30, ao mesmo tempo em que reconhece como seu limite de análise a ideia de que o ponto fulcral dessa ideologia é a tentativa de domesticar o mercado (SILVA, 2004). 
um poder centralizado e a falta de caráter estrategista que tornavam o Estado ilegítimo; jamais sua autoridade. Por consolidar um Estado capaz de superar o quadro de crise vigente, romper com o liberalismo anômico e realizar o interesse nacional, a ideologia de Estado do PAB exprimia um verdadeiro idealismo orgânico (VIANNA, 1939).

Apelando à conveniência e adequação à realidade nacional, e à tendência da evolução política mundial de substituir a competência parlamentar pela técnica, propunha a fundação de uma nova ordem caracterizada pela: 1) preeminência do Estado sobre a sociedade civil; 2) preeminência do Executivo sobre o Legislativo e o Judiciário; e 3) preeminência das elites técnicas sobre as elites políticas (SILVA, 2004). Em suma, a construção de um Estado autoritário que, apoiado em uma inteligência técnica e científica, organizada em corporações, tornar-se-ia grande intérprete e real representante do povo. Segundo Vianna, o Estado autoritário corporativo exprimia "um verdadeiro regime de opinião, de um sistema de governo verdadeiramente popular, intérprete real dos interesses do povo e infinitamente muito mais democrático do que aquele que há cem anos, estamos procurando realizar" (VIANNA, 1974a, p.145).

É, pois, perceptível o alto grau de sistematização de ideias alcançado por esse grupo em detrimento dos demais. Não obstante tratar-se de um período de amplo debate político e social, as demais correntes em disputa encontravam-se fragilmente estruturadas chegando, mesmo, a desaparecer durante a luta política. Em face deste protagonismo ideológico do $\mathrm{PAB}$, o presente artigo procura identificar qual foi a influência dessas ideias sobre os textos constitucionais de 1934 e 1937.

Nossa opção pelo estudo das Constituições explica-se, primeiramente, pelo caráter legal imputado a uma Constituição: definir os rumos e limites da ação do Estado, racionalizando-o, tornando-o expressão da vontade coletiva e, por isso, legítimo (GOZZI, 2004). Somado ao papel extremamente peculiar e central que as Constituições desempenham no plano nacional: o de refundar o Estado com vistas ao desenvolvimento, o que as torna esferas de disputa política e mecanismo preferencial à disseminação de ideias (GOMES, 1980). Ademais, o ambiente de grande efervescência política e cultural que caracterizou os anos 30, gerou uma articulação entre organização in- 
telectual e aparelho de Estado (PÉCAUT, 1990). Uma vez que a grande maioria dos intelectuais esteve vinculada ao Estado (direta ou indiretamente), o estudo da influência autoritária (ou de qualquer outro grupo) por meio da análise de seu grau de participação nas esferas estatais tenderia ser subestimada. Diante disso, optamos por analisar a influência política das ideias autoritárias a partir de sua maior ou menor assimilação nos dois textos constitucionais do período.

Pautados na concepção das ideias como perspectiva política mobilizada - constituem fenômenos socialmente construídos que se influenciam reciprocamente; surgem como uma necessidade histórico-social da vida de modo a diagnosticar problemas e/ou propor caminhos (LUKÁCS, 1981) - buscamos analisar essas Constituições não como meros textos jurídicos, mas como legislações inseridas em um ambiente político-cultural específico. A hipótese que norteia o trabalho é a de que, por conta do grau de sistematização de suas ideias, o PAB exerceu papel determinante sobre ambos os textos. Nesse sentido, a conhecida diferença entre essas Cartas reflete o próprio processo de maturação política e ideológica do grupo, mais do que uma suposta pressão por parte dos demais. Procuramos, assim, ampliar o debate acerca deste conturbado período da história nacional e, ao mesmo tempo, contribuir ao estudo destas duas Constituições: peças-chaves dos anos 30, porém ainda alvos de "pré-conceitos" que obscurecem sua real compreensão.

Este trabalho encontra-se estruturado da seguinte forma: observamos se, e como, algumas categorias da ideologia de Estado do $\mathrm{PAB}$ aparecem nestes textos constitucionais - discurso da crise, antiliberalismo, elitismo, nacionalismo, corporativismo e autoritarismo. Ao mesmo tempo, de modo a verificar se essas referências são exclusivas às Cartas dos anos 30 ou se derivam de um processo natural e/ou mundial de mudança do modelo de Estado, estabelecemos um comparativo com as Cartas de 1891 e 1946. Trata-se de uma análise de conteúdo orientada em torno das seguintes questões: Que força tem o poder Executivo? Que influência efetiva tem os demais poderes na política nacional? Qual é o nível de autonomia política estadual e municipal? Qual é o nível de liberdade existente? Há censura? Se sim, sobre o que se aplica e como? Como está organizada a economia? 


\section{As Constituições dos anos 30 em perspectiva com- parada}

\subsection{4 versus 1891}

A Constituição de 1934 situa-se no terreno intermediário entre as Cartas de 1891 e 1937, não é tão liberal como a de 1891, nem tão autoritária como a de 1937. Define-se como um texto constitucional híbrido: agrega elementos das principais correntes em debate, consagrando um Estado tipicamente liberal em alguns aspectos e essencialmente autoritário em outros. Sucintamente poderíamos caracterizar a Constituição de 1934 da seguinte maneira: 1) mantém o mesmo Poder Executivo da Carta de 1891 - um Executivo com atribuições restritas e condicionadas à aprovação do Legislativo; 2) instaura um Poder Legislativo ainda mais forte e controlador que o de 1891, embora incorporando princípios corporativos; 3) fortalece os poderes da União em detrimento do poder dos estados, em um sentido claro de superação da excessiva descentralização política característica de 1891; e 4) confere ao Estado um conteúdo mais interventor, passando a regular matérias como educação, trabalho e, principalmente, economia. Supera, pois, os aspectos polêmicos da Carta de 1891, porém sem chegar a estruturar as condições necessárias para suplantar suas causas. Vejamos por quê.

Ao avaliarmos a Carta de 1934, de início já nos chama atenção seus primeiros dizeres: "Nós, os representantes do povo brasileiro, pondo a nossa confiança em Deus, reunidos em Assembléia Nacional Constituinte para organizar um regime democrático que assegure à Nação a unidade, a liberdade, a justiça e o bem-estar social e econômico, decretamos e promulgamos a seguinte Constituição" (Constituição de 1934). Tais dizeres são mais do que uma simples apresentação ou justificativa da Carta, revelam muito da tônica de seus artigos quando se mesclam princípios liberais com autoritários em nome do bem coletivo e apoiado em Deus.

Em termos práticos ela é a mais longa dentre todas as outras Constituições. Possui 187 artigos e mais 26 disposições gerais e transitórias, perdendo apenas para a Carta de 1946, que soma ao todo 222 artigos. Dentre estes 187 artigos, cerca de 40 referem-se 
exclusivamente à organização do Poder Legislativo, 10 ao Poder Executivo e uns 25 ao Poder Judiciário. É claro o destaque ocupado pelos órgãos legislativos, cujas atribuições não diferem muito das prescritas em 1891. Passam apenas a incluir matérias de caráter mais intervencionista como "traçar as diretrizes da educação nacional; legislar sobre bens de domínio federal, riquezas do subsolo, mineração, condições de capacidade para o exercício de profissões liberais e técnico-científicas, assim como a do jornalismo" (Constituição de 1934, artigo 5). Todavia, a despeito desta primeira impressão de constância, esta Carta traz importantes inovações.

A primeira e principal reside na nova composição da Câmara dos Deputados que passa a incorporar representantes das profissões nacionais - "a Câmara dos Deputados compõe-se de representantes do povo, eleitos mediante sistema proporcional e sufrágio universal, igual e direto, e de representantes eleitos pelas organizações profissionais, na forma que a lei indicar" (Constituição de 1934, artigo 23). Essa medida tem dois significados centrais: reflete a incorporação de princípios nacionalistas autoritários incompatíveis com um regime político liberal e, em decorrência, concede à Câmara um novo caráter, pois estrutura um novo mecanismo para a representação da sociedade. Sendo assim, a representação profissional reduz o conteúdo excessivamente liberal de algumas atribuições legislativas, tornando-o um verdadeiro órgão não só à expressão, mas, sobretudo, à realização da vontade coletiva.

Outro aspecto inovador refere-se ao Senado Federal. Buscando apaziguar os interesses em debate e solucionar os problemas de controle da constitucionalidade e quebra do equilíbrio entre os poderes, esta Carta estrutura o Senado Federal como órgão de Coordenação dos Poderes ${ }^{6}$. Cabe ao Senado "promover a coordenação dos poderes federais entre si, manter a continuidade administrativa, velar pela Constituição, colaborar na feitura das leis e praticar os demais atos de sua competência" (Constituição de 1934, artigo 88).

6 Duas orientações estavam em disputa no período: de um lado as oligarquias, voltada à manutenção do atual sistema político; de outro os nacionalistas autoritários, fiéis defensores de um sistema unicameral. Deste embate emerge o novo Senado Federal a quem compete funções tanto legislativas - praticamente as mesmas de 1891 - quanto de coordenação dos poderes (GOMES, 1990). 
Assume, assim, papel de órgão fiscalizador e jurisdicional, de certo modo deslocado do Poder Legislativo - espécie de reminiscência da ideia autoritária de Poder Coordenador ou Moderador que nesta Carta sofre uma inversão: deixa de ser um mecanismo de controle do chefe de Estado, para se tornar um órgão de controle legislativo sobre o Executivo (GOMES, 1990).

Por fim, a última grande novidade desta Carta são os órgãos de colaboração do Estado, com destaque para os Conselhos Técnicos: "órgãos consultivos da Câmara dos Deputados e do Senado Federal" (Constituição de 1934, artigo 103). Tais Conselhos visam auxiliar na tomada de decisões, de modo a ampliar a racionalidade da atividade governamental e adequá-la às necessidades e características nacionais. Assinalam um importante passo em direção à proposta autoritária de Estado em sentido claro ao rompimento com um dos principais postulados do texto de 1891: o do livre funcionamento do mercado. Apesar de esta Carta não prescrever a composição, funcionamento e competência desses órgãos, sua simples criação já inaugura (de certa forma) o processo de corporativização da economia nacional.

A despeito destas inclinações ao modelo autoritário de Estado, é importante frisar que o liberalismo é uma constante nesta Carta, especialmente em sua organização dos poderes. Por mais que ela prescreva uma Câmara composta de representantes profissionais, um Senado com função de coordenação dos Poderes, e Conselhos Técnicos para ajudar na administração estatal, subsiste em seus artigos uma forte tendência liberal voltada ao controle do poder de intervenção do governo. Segundo Poletti, a principal ideia que orientou a Carta de 1934 foi a de conter o Executivo, do que resultou um texto altamente restritivo:

Competia ao Presidente decretar o estado de sítio. Mas quem lhe autorizava a medida era o Poder Legislativo. Se não estivessem reunidos a Câmara e o Senado, o presidente da República deveria obter aquiescência prévia da sessão permanente do Senado e, nessa hipótese, as Casas se reuniriam dentro de trinta dias, independentemente de convocação (...) De igual maneira, competia ao Presidente da República intervir nos Estados ou neles executar a intervenção. No entanto, a intervenção para garantir a observância 
dos princípios constitucionais seria decretada por lei federal, que lhe fixaria a amplitude e duração, prorrogável por nova lei. (...) sempre o Legislativo dava a última palavra (POLETTI, 1999, p. 44).

De modo geral, as atribuições executivas não diferem muito das prescritas em 1891. Ambas as Cartas limitam-nas a tarefas meramente administrativas de caráter técnico, com a diferença de que em 1934 sua realização passa a depender ainda mais da aprovação do Legislativo. Sua principal função (e praticamente a única) é "sancionar as leis elaboradas pelo Legislativo e expedir os regulamentos necessários para sua fiel execução" (Constituição de 1934, artigo 56). Define-se, pois, como um Executivo amorfo, cujo papel é zelar pela manutenção da ordem.

Ao nível da organização federal, esta Carta supera o excessivo federalismo de 1891, restituindo à União grande parte de sua autoridade: se em 1891 competiam-lhes decretar a maioria dos impostos, em 1934 isto não só passa a estar a cargo da União, como lhes é também vetado o direito de tributar as propriedades urbanas de seu próprio território (Constituição de 1981, artigo 9; Constituição de 1934, artigo 5). Ademais, na Carta de 1934 não são apenas as competências estaduais que são restringidas, mas também suas permissões: enquanto em 1891 era defeso aos estados recusar fé aos documentos públicos e declarar guerra entre si, em 1934 isso lhes é rigorosamente proibido, sendo, em contrapartida, incentivada sua constante cooperação (Constituição de 1981, artigo 8; Constituição de 1934 artigos 7 e 10). Não bastando, esta Carta também restringe consideravelmente os bens sob domínio estadual (Constituição de 1934, artigos 7 a 12). Logo, o domínio que lhes era tão amplo em 1891 é restrito em 1934 e, na maioria dos casos, em favor da União. Este fato aponta para o viés centralizador e nacionalista de algumas de suas disposições.

Diferentemente da Carta de 1891, o texto de 1934 não prevê direitos individuais tão amplos, ainda que sejam praticamente os mesmos. Ao direito de associação incorpora-se o termo "para fins lícitos", e de modo a evitar que as reuniões representem um perigo à ordem pública, as autoridades podem "designar o local onde a reunião se deva realizar". A livre manifestação do pensamento in- 
dependente de censura deixa de valer nos casos de "espetáculos e diversões públicas", e se estabelece a seguinte ressalva à liberdade de publicação: "não será tolerada propaganda de guerra ou de processos violentos para subverter a ordem política ou social". O livre exercício de qualquer profissão passa a depender "de capacidade técnica e outras que a lei estabelecer, ditadas pelo interesse público". Por fim, a mais importante de todas as ressalvas, o direito de propriedade passa a estar limitado à sua "não oposição ao interesse coletivo" (Constituição de 1934, artigo 113).

Estas modificações apontam para a constante preocupação desta Carta em possibilitar não apenas a manutenção da ordem, mas também a realização dos interesses sociais ou coletivos. Isso se faz mais evidente no que consta à organização da economia: "deve ser organizada conforme os princípios da justiça e as necessidades da vida nacional, de modo que possibilite a todos existência digna. Dentro desses limites é garantida a liberdade econômica" (Constituição de 1934, artigo 115). A liberdade econômica, tão cara à Carta de 1891, aparece aqui limitada ao interesse coletivo, ao mesmo tempo em que a intervenção governamental impõe-se não apenas como direito do Estado, mas como uma necessidade da nação, fazendo-se, por conseguinte, uma constante. Consolida, pois, um sistema econômico em que há limites claros à iniciativa individual.

Além disso, é importante destacar que a Carta de 1934, diferentemente da de 1891, tem nítidas preocupações sociais. Incorpora em seu texto títulos inteiros destinados à regulamentação da ordem social, da família, educação e cultura, impensáveis em 1891. Os artigos que os compõem determinam as situações e a extensão do apoio governamental, ao mesmo tempo em que estruturam uma intensiva política de nacionalização dessas atividades (Constituição de 1934, título V).

Em resumo, fica claro que a Carta de 1934 busca, ao longo de seus 187 artigos, apaziguar as ideias e os interesses em conflito. Estrutura um Estado menos descentralizado que o de 1891, com uma União fortalecida, mas um Executivo igualmente amorfo; instaura um Legislativo confuso, onde convivem a representação profissional da sociedade, um órgão de coordenação dos poderes, e o mesmo viés liberal de controle do Executivo. Ademais, limita os direitos e regulamenta a economia em sentido à realização de propósitos 
sociais e não de meros interesses econômicos. Mantém, portanto, uma rígida posição liberal em alguns pontos, ao mesmo tempo em que caminha para um crescente intervencionismo em outros. Como consequiência, define-se como um texto ambíguo que camufla os principais problemas nacionais, sem conseguir efetivamente superálos, abrindo espaço à outorgação da Carta de 1937.

\subsection{7 versus 1934 e 1891:}

Podemos dizer que o texto constitucional de 1937 conclui o processo iniciado pela Carta de 1934: instaura um Estado altamente centralizado pautado por processos corporativos. É o inverso da Carta de 1891, o Legislativo se encontra limitado pelo Executivo, os estados são diretamente controlados pela União, são impostos rígidos controles aos direitos do homem, e a economia é claramente controlada pelo Estado. Em seus primeiros artigos incita o centralismo presente por todo o texto: "a bandeira, o hino, o escudo e as armas nacionais são de uso obrigatório em todo o País. Não haverá outras bandeiras, hinos, escudos e armas. A lei regulará o uso dos símbolos nacionais" (Constituição de 1937, artigo 2). Ainda que possamos pensar ser esta uma temática boba, ao estabelecer a obrigatoriedade do uso dos símbolos nacionais e eliminar a possibilidade de existência de qualquer outro, esta Carta está de fato suprimindo a autonomia dos estados, submetendo-os ao rígido controle da União. Enquanto as demais Cartas prescrevem rígidas condições e controles à intervenção federal nos estados, aqui ela se estrutura mais do que como um direito, antes como uma obrigação. Vejamos.

É tarefa do governo federal: intervir "nos estados mediante a nomeação, pelo Presidente da República, de um interventor, que assumirá no estado as funções que, pela sua Constituição, competirem ao Poder Executivo, ou as que, de acordo com as conveniências e necessidades de cada caso, lhe forem atribuídas pelo Presidente da República" - a saber: para restabelecer a ordem alterada ou para administrar o estado (Constituição de 1937, artigo 9). Já aos estados faculta-se o direito de "exercer todo e qualquer poder que não lhes seja negado por esta Constituição" (Constituição de 1937, artigo 21). Uma vez que quase todas as esferas de ação são destinadas ou 
controladas pela União (leiam Executivo Federal), somado ao fato de que é competência do Presidente da República intervir nos estados, independentemente de qualquer autorização do Congresso, restalhes de fato pouca margem de liberdade e poder.

Além disso, esta Carta atribui ao Presidente da República o direito de legislar por meio de decretos-leis. Apesar de especificados limites ao usufruto deste direito - "nos períodos de recesso do Parlamento ou de dissolução da Câmara dos Deputados" e livremente "sobre a organização do Governo e da administração federal, o comando supremo e a organização das Forças Armadas" (Constituição de 1937, artigo 15) - estes artigos coroam a total eliminação do princípio da separação e independência dos poderes, concedendo ao Executivo carta branca nas matérias legislativas. Isso é ainda mais evidente quando observamos a composição e quais funções competem ao Parlamento:

"Art. 38. O Poder Legislativo é exercido pelo Parlamento Nacional, com a colaboração do Conselho de Economia Nacional e do Presidente da República (...)

O Parlamento Nacional compõe-se de duas Câmaras: a Câmara dos Deputados e o Conselho Federal.

A Câmara dos Deputados compõe-se de representantes do povo, eleitos mediante sufrágio indireto.

O Conselho Federal compõe-se de representantes dos estados e dez membros nomeados pelo Presidente da República.

Art. 64. A iniciativa dos projetos de lei cabe, em princípio, ao Governo (...)

$\S 1 \stackrel{0}{ }$. A nenhum membro de qualquer das Câmaras caberá a iniciativa de projetos de lei. A iniciativa só poderá ser tomada por um terço de deputados ou membros do Conselho Federal.

$\S 2$. Q Qualquer projeto incitado em uma das Câmaras terá suspenso o seu andamento, desde que o Governo comunique seu propósito de apresentar projeto que regule o mesmo assunto".

(Constituição de 1934. Grifos nossos)

Compete, pois, ao Presidente da República tanto estruturar o Poder Legislativo, como legislar. A liberdade de iniciativa e de legislação do Poder Legislativo é reduzida a praticamente zero, em detrimento de sua ampliação à esfera executiva. 
Soma-se a isso uma forte inclinação à tecnificação do trabalho parlamentar expressa no Conselho de Economia Nacional e Departamento Administrativo. Estes órgãos não apenas controlam a atividade parlamentar, de fato, suprimem-lhe o direito ao exercício de antigas e importantes funções. Compete ao Departamento Administrativo estudar de forma pormenorizada os recursos disponíveis e as necessidades nacionais existentes, para alocá-los da maneira mais econômica e eficiente possível; organizar anualmente a proposta orçamentária e fiscalizar sua execução (Constituição de 1937, artigo 67). Ao Conselho de Economia Nacional cabe "emitir parecer sobre todos os projetos de iniciativa do Governo ou de qualquer das Câmaras, que interessem diretamente à produção nacional", podendo adquirir "poderes de legislação sobre algumas ou todas as matérias de sua competência” (Constituição de 1937, artigo 61). Seus resultados imediatos são: 1) retirar do Parlamento a atribuição de fazer e votar a proposta orçamentária do governo; 2) privar-lhe do poder de legislar sobre as matérias econômicas, colocando-a nas mãos de representantes profissionais. Consagram a percepção dessas matérias como atividades técnicas e não políticas, corroborando à centralização da política na esfera executiva, bem como à burocratização e corporativização de determinadas funções do Estado. Ademais, apela para a tecnificação e racionalização da atividade administrativa como condição à realização do bem-coletivo.

Esse mesmo interesse coletivo é posto acima de qualquer prerrogativa individual - "o uso dos direitos e garantias individuais terá por limite o bem público, as necessidades da defesa, do bem-estar, da paz e da ordem coletiva, bem como as exigências da segurança da Nação e do Estado em nome dela constituído e organizado nesta Constituição" (Constituição de 1937, artigo 123) - do que deriva direitos bastante restritos. Enquanto as demais Cartas se referem à inviolabilidade dos direitos concernentes à liberdade, à segurança individual e à propriedade esta se limita a dizer: "a Constituição assegura aos brasileiros residentes no País o direito à liberdade, à segurança individual e à propriedade" (Constituição de 1937, artigo 122).

De modo geral, os direitos individuais são os mesmos da Carta de 1934, porém seus limites são bem mais rigorosos, levando quase que a sua total extinção. Por exemplo: é garantida ao indiví- 
duo a liberdade de associação, mas "desde que seus fins não sejam contrários à lei penal e aos bons costumes"; todos têm o direito de se reunir pacificamente, contudo as reuniões a céu aberto contam agora com o constrangimento de se submeterem "à formalidade de declaração", podendo ser interditadas tão logo representem "perigo imediato para a segurança pública”; a liberdade ao livre exercício de qualquer profissão, já restrita na Carta de 1934 às condições da capacidade, agora enfrenta também as "restrições impostas pelo bem público nos termos da lei”. Não bastando, o direito à manifestação do pensamento é assegurado "mediante as condições prescritas em lei”; lei responsável não apenas por instituir a censura prévia dos meios de comunicação, mas também por designar a impressa como órgão de caráter público, submetido ao interesse nacional, aos desígnios do governo (Constituição de 1937, artigo 122).

A substância autoritária dessa Carta faz-se ainda mais evidente frente à determinação de casos cabíveis de pena de morte: "tentar, por meio de movimento armado, o desmembramento do território nacional; (...) a mudança da ordem política ou social estabelecida pela Constituição; (...) [ou] subverter, por meios violentos, a ordem política e social, com o fim de apoderar-se do Estado para o estabelecimento da ditadura de uma classe social" (Constituição de 1937, artigo 122). Ainda que este parágrafo resulte em grande parte do clima de insegurança vivenciado no país desde o início do século (sobretudo, do medo da ameaça comunista), assinala de forma contundente seu autoritarismo. Na medida em que são impostos rigorosos limites ao direito de expressão, de associação e de organização da sociedade, associado ao fato de que a pena prescrita às possíveis ameaças à ordem é a morte, retira-se do indivíduo toda e qualquer liberdade que possa ter lhe restado. A inviolabilidade da segurança do Estado, traduzida em termos da realização do interesse coletivo, é colocada acima de qualquer direito individual; tônica também presente nos parágrafos que versam sobre a organização da economia, legislação trabalhista e organização profissional da sociedade.

De modo geral, podemos dizer que esta Carta fortalece os limites econômicos já prescritos na Constituição de 1934: permite a iniciativa individual "exercida nos limites do bem público" para o que se legitima a intervenção estatal no domínio econômico (Cons- 
tituição de 1937, artigo 135. Grifos nossos). Estabelece uma ampla legislação trabalhista, que atua de fato na domesticação da opinião pública: concebe o trabalho como um dever social; proíbe a greve por se tratar de recurso anti-social, nocivo ao trabalho, incompatível com os interesses nacionais; e limita os canais de expressão das demandas sociais às associações reconhecidas pelo Estado (Constituição de 1937, artigo 136 e 137). Por fim, propõe a corporativização da economia nacional, porém evocando-a menos como um mecanismo de representação política da sociedade e mais como um mecanismo de seu controle pelo Estado: tratam-se de "entidades representativas das forças do trabalho nacional, colocadas sob a assistência e a proteção do Estado, são órgãos deste e exercem funções delegadas pelo poder público" (Constituição de 1937, artigo 140).

Essa política de domesticação da opinião pública e corporativização da sociedade também estão presentes na organização da educação. A Carta de 1937 é a única que: 1) prescreve a obrigatoriedade da educação física, do ensino cívico e do ensino de trabalhos normais; 2) prevê a fundação de instituições destinadas a organizar a juventude; e 3) institui como dever das indústrias e sindicatos criar escolas de aprendizes. Buscando "promover a disciplina moral e o adestramento físico [da juventude] de maneira a prepará-la ao cumprimento dos seus deveres para com a economia e a defesa da nação", pressupõe a educação como veículo ao controle da sociedade e desenvolvimento nacional (Constituição de 1937, artigo 132).

Se tudo isso já ratifica o alto grau de autoritarismo desta Carta, suas disposições a respeito da segurança nacional concedem poderes de natureza ditatorial ao chefe do Executivo: "em caso de ameaça externa ou iminência de perturbações internas, ou existência de concreto plano ou conspiração (...) poderá o Presidente da República declarar o estado de emergência (...) Para nenhum desses atos será necessária a autorização do Parlamento Nacional, nem este poderá suspender o estado de emergência ou estado de guerra declarado pelo Presidente da República" (Constituição de 1937, artigo 166). Consagra, portanto, não um mero Estado autoritário, mas antes uma verdadeira ditadura.

Em entrevista ao Jornal Correio da Manhã em março de 1945, Francisco Campos defendeu a Constituição de 1937. Segundo ele 
"os males que, porventura, tenham resultado para o País do regime inaugurado pelo Golpe de Estado de 1937 não podem ser atribuídos à Constituição. Esta não chegou sequer a vigorar. E, se tivesse vigorado, teria, certamente, constituído importante limitação ao exercício do poder" (CAMPOS apud. PORTO, 1999). Se por um lado o autor tem razão, a Constituição efetivamente não vigorou, por outro ele está totalmente errado. Praticamente inexistiam limites ao livre exercício do poder pelo Executivo.

O que pudemos averiguar ao longo da análise desta Carta é que ela não só supera completamente o liberalismo de 1981 e 1934, como institui para seu lugar um Estado autoritário. O regime inaugurado pela Carta de 1937 é altamente centralizador: concede ao chefe do Executivo autoridade sobre todos os domínios nacionais; restringe radicalmente os poderes e as funções do Legislativo, instituindo para seu lugar órgãos de caráter técnico, com vistas a apolitizar a atividade parlamentar; impõe severos limites ao livre gozo dos direitos individuais, ao mesmo tempo em que estabelece canais precisos para a representação da sociedade; por fim, defende a construção de uma economia corporativa, que se assemelha mais ao corporativismo dirigista do século XX do que à prática de uma democracia orgânica. Ao compará-la com a Carta de 1946 tal viés autoritário fica ainda mais evidente.

\subsection{4 e 1937 versus 1946}

A Carta de 1946 representa a opção brasileira pela via capitalista no pós-guerra. Consolida, a seu modo, um Estado socialdemocrático; modelo então vigente em quase toda a Europa. De modo geral, esta Carta tem o significado de restituir ao país o poder e a autonomia dos estados e dos municípios, e resgatar o princípio da divisão e independência dos poderes à atividade política, sem prejuízo a nenhuma das esferas envolvidas. Situa-se, portanto, no terreno intermediário às Cartas de 1934 e de 1937.

No nível da organização federal, assegura à União as mesmas atribuições prescritas no texto de 1934, com a diferença de que estas passam a competir, ao mesmo tempo, ao Legislativo (em maior número) e ao Executivo. Ademais, tais funções não se impõem sobre 
os domínios dos estados e municípios. Aos estados assegura-se, novamente, o direito de estabelecer suas Constituições e as leis pelas quais se regerão, e o fazem dentro de limites bem mais amplos que os existentes em 1937. Competem-lhes direitos, teoricamente, também prescritos em 1934 e 1937, mas, efetivamente, nunca postos em prática. Sua autonomia é até mesmo maior que a de 1934, pois enquanto esta Carta possibilitava a intervenção da União para reorganizar as finanças dos estados, aqui sua ação fica reduzida ao dever de "prestar-lhes socorro em caso de calamidade pública" (Constituição de 1946, artigo 16). No que tange aos municípios sua autonomia fica assegurada "pela eleição dos prefeitos e vereadores", eleição esta que tende a ser mais racional e, por conseguinte, mais justa haja vista a ampliação do sufrágio e instituição do Tribunal Eleitoral (Constituição de 1946, artigo 28 e 110). Estrutura, assim, uma ordem em que nenhuma esfera de poder se sobrepõe ao domínio das outras.

Já ao nível da divisão e organização dos poderes, esta Carta busca conter a atual força do chefe do Executivo, restaurando ao Legislativo e Judiciário seus respectivos poderes. Comparativamente às Constituições de 30, estrutura um Legislativo nos moldes da Carta de 1934, porém com um caráter menos limitador do Executivo. Ao mesmo tempo, supera a bagunça instaurada em 1934, e aprofundada em 1937, estruturando um Legislativo dentro de seus moldes clássicos: restitui o Senado Federal de funções puramente legislativas e restaura à Câmara dos Deputados sua antiga composição - "representantes do povo eleitos, segundo o sistema de representação proporcional" (Constituição de 1946, artigo 56). Ademais, prescreve ao Legislativo a iniciativa das leis em comunhão com o Presidente da República, salvo "os casos de competência exclusiva" (Constituição de 1946, artigo 67). Demarca, precisamente, o campo de ação de cada um dos três poderes.

Vale destacar também que ao nível do Poder Legislativo esta Carta traz duas importantes inovações. Prevê: 1) reunião do Congresso Nacional de 15 de março a 15 de dezembro, com as duas casas trabalhando em sessão separada; 2 ) instituição de um Tribunal de Contas, composto de membros nomeados pelo Presidente da República e aprovados pelo Senado, para acompanhar e fiscalizar a execução do orçamento (Constituição de 1946, artigo 39 e 76). 
Enquanto medida, visa fazer a atividade do Legislativo uma constante à administração do país, contendo possíveis constrangimentos e/ou abusos que seu recesso pudesse significar; a segunda comunga do ideal estadonovista de apolitizar a atividade administrativa, criando um órgão específico, deslocado do jogo político, para executar uma atividade anteriormente situada no rol das funções parlamentares. O Tribunal de Contas tem o propósito de intensificar a tomada de contas dos órgãos públicos, racionalizando-se, assim, seu uso. Ambas as medidas agem, portanto, em sentido à formação de um Legislativo mais presente e operante, mas longe de se impor ao Executivo.

O Poder Executivo de 1946 não é nem o Executivo centralizador de 1937, nem o completamente dependente de 1934. Embora as competências que lhe cabem sejam quase as mesmas prescritas em 1934, a inexistência de um órgão de coordenação dos poderes lhe confere maior liberdade de ação. Além disso, enquanto em 1934 estavam devidamente prescritos os casos e as condições de processo e julgamento do Presidente da República, esta Carta limita-se em definir os casos que constituem crimes de sua responsabilidade (Constituição de 1946, artigo 89). Cada poder tem, pois, assegurado a liberdade de iniciativa em seus respectivos domínios.

No que concerne aos direitos e à economia, esta Carta segue um viés social-democrático e ao mesmo tempo nacionalista. Procura estruturar um sistema político e econômico que assegure a manutenção da ordem e a racionalidade do sistema político, ao mesmo tempo em que promova condições dignas de existência a todos e o pleno desenvolvimento nacional. Ao nível dos direitos e garantias individuais, praticamente restabelece os mesmos direitos, as condições e os limites de seu usufruto, já prescritos no texto de 1934. Sua única novidade resulta do artigo que restringe a organização política aos partidos ou associações "cujo programa ou ação contrarie o regime democrático" (Constituição de 1946, artigo 141). Este artigo é antes um indicativo do momento que se vivia (o medo do comunismo pairava sobre o mundo), do que uma postura restritiva. Nesta Carta a organização política da sociedade deixa efetivamente de ser um negócio de polícia, abrindo-se as portas à real participação.

Esta orientação mais democrática também é visível diante da imposição de certos limites para a cobrança de impostos pelo 
governo - a saber: "artigos que a lei classificar como o mínimo indispensável à habitação, vestuário, alimentação e tratamento médico das pessoas de restrita capacidade econômica; sobre sítios de área não excedente a vinte hectares, quando os cultive, só ou com a família, o proprietário que não possua outro imóvel (Constituição de 1946, artigo 15). Expressam uma atividade governamental orientada em sentido à promoção do bem coletivo e de garantia de condições dignas à sobrevivência de todos; ideia também visível em sua organização da economia.

Prescreve que a ordem econômica deve ser organizada "conforme princípios da justiça social, conciliando a liberdade de iniciativa com a valorização do trabalho humano" (Constituição de 1946, artigo 145). Combina, aí, o viés social e nacionalista inaugurado pelo texto de 1934, com partes da organização trabalhista consagrada em 1937, do que resulta uma economia com propósitos visivelmente social e acompanhada de um Estado menos interventor. Embora, regulamente, o trabalho com base em princípios estadonovistas "o trabalho é uma obrigação social; é livre a associação profissional e sindical, sendo reguladas por lei" (Constituição de 1946, artigo 145) - ela reconhece o direito de greve, conferindo, assim, melhores condições à expressão e representação dos trabalhadores. Ademais, suas disposições sobre a propriedade e a intervenção estatal - "o uso da propriedade será condicionado ao bem-estar social; a lei reprimirá toda e qualquer forma de abuso econômico (...) que tenham por fim dominar os mercados nacionais" (Constituição de 1946, artigo 145) - evidenciam seu intento em assegurar a realização do interesse coletivo sem que isso resulte em alguma perda à sociedade ou a iniciativa privada.

A economia de 1946 é, portanto, quase que um completo resgate do modelo econômico de 1934, porém pincelado de alguns mecanismos característicos de 1937. Exemplo disso é a criação do Conselho Nacional de Economia, variação do Conselho de Economia Nacional de 1937, que aqui perde seu caráter legislativo, tornandose mais um instrumento de colaboração do governo - "incumbe ao Conselho estudar a vida econômica do País e sugerir ao Poder competente as medidas que considerar necessárias" (Constituição de 1946, artigo 205). Assinala, pois, a adaptação de um mesmo 
mecanismo às exigências dos novos tempos; fato este que, como vimos, faz-se presente ao longo de todo seu texto.

Em resumo, a Carta de 1946 assinala uma espécie de resgate e de superação dos textos constitucionais dos anos 30. Se temos a impressão de que ela simplesmente repete algumas disposições destas outras Cartas, é porque realmente o faz. Ela comunga inteiramente de artigos e mecanismos consagrados em ambas as Cartas (especialmente da de 1934), porém ajustando-as ao novo contexto vivido e superando seus principais limites: sua inadequação às condições e/ou necessidades nacionais. Estrutura um regime onde o coletivo se sobrepõe ao indivíduo, porém sem ser autoritário; onde União, estados e municípios têm poder e autonomia suficientes à realização de seus interesses específicos, sem que isso resulte em um ultra federalismo ou ultra centralismo; onde Executivo, Legislativo e Judiciário convivem efetivamente como poderes "independentes e coordenados", sem que a autoridade de um constranja a dos demais; e, até mesmo, onde algumas atividades governamentais são tecnificadas, mas não em detrimento do poder de outros. Organiza, portanto, um Estado que bebe nos textos constitucionais dos anos 30 , porém sem reportar o autoritarismo de 1937, ou a miscelânea de ideias de 1934. Revela, assim, o que é contingente e o que é meramente ideológico nestes textos.

\section{O pensamento autoritário e as Constituições dos anos 30}

Terminada a análise das duas Constituições em debate, comparativamente às Cartas de 1891 e 1946, temos claro quais foram suas inovações e influências. De certo modo, ambas assinalaram um processo de passagem; a tentativa de construção de uma nova etapa que superava o momento vivido. A Carta de 1934 marcou a superação do ultra federalismo de 1891 e o abandono do liberalismo no plano econômico, passando a incorporar uma perspectiva mais centralizadora e nacionalista que impunha limites à iniciativa individual. Já o texto de 1937 expressou a superação do liberalismo também no plano político, instituindo um Executivo altamente centralizado que suprimiu qualquer princípio federalista ou de divisão 
dos poderes, em uma clara tentativa de corporativização da política, economia e sociedade nacionais. Procurando responder ao debate político-cultural em voga, acabaram por assimilar alguns princípios autoritários do $\mathrm{PAB}$, mesmo quando incoerentes com o modelo de Estado que "pretendiam estruturar".

No quadro analítico abaixo podemos ver de que forma os temas do PAB foram incorporados por essas duas Constituições:

\section{Quadro Analítico: As Constituições dos anos 30 e o PAB}

\begin{tabular}{|c|c|c|}
\hline $\begin{array}{c}\text { Temas } \\
\text { do PAB }\end{array}$ & Carta de 1934 & Carta de 1937 \\
\hline $\begin{array}{l}\text { DISCURSO } \\
\text { DA CRISE }\end{array}$ & $\begin{array}{l}\text { * está implícito em seus dizeres } \\
\text { iniciais: } \\
\text { "organizar regime democrático } \\
\text { que assegure à nação unidade, } \\
\text { liberdade, justiça e bem-estar" }\end{array}$ & $\begin{array}{l}\text { * encontra explícito em seus dizeres } \\
\text { iniciais: } \\
\text { "O Presidente da República, atendendo } \\
\text { às aspirações à paz política e social } \\
\text { resolve assegurar condições necessárias } \\
\text { à segurança, bem-estar e prosperidade" }\end{array}$ \\
\hline $\begin{array}{l}\text { ANTILIBE- } \\
\text { RALISMO }\end{array}$ & $\begin{array}{l}\text { "refere-se apenas à sua forma } \\
\text { econômica: } \\
\text { "ordem econômica organizada } \\
\text { conforme princípios de justiça e } \\
\text { necessidades da vida nacional" } \\
\text { "direito de propriedade não pode } \\
\text { ser exercido contra o interesse } \\
\text { social ou coletivo" }\end{array}$ & $\begin{array}{l}\text { * presente tanto em sua organização da } \\
\text { economia, como da atividade política: } \\
\text { "O governo federal intervirá nos estados } \\
\text { mediante a nomeação de um interven- } \\
\text { tor" } \\
\text { "O Presidente da República poderá } \\
\text { expedir livremente decretos-leis" } \\
\text { "É legítima a intervenção do Estado no } \\
\text { domínio econômico para coordenar os } \\
\text { fatores de produção" }\end{array}$ \\
\hline ELITISMO & $\begin{array}{l}\text { * presente em seus dispositivos de } \\
\text { corporativização e tecnificação do } \\
\text { trabalho político que restringem o } \\
\text { sufrágio em seu caráter participati- } \\
\text { vo e eletivo: } \\
\text { "representação corporativa na Câ- } \\
\text { mara dos Deputados + Conselhos } \\
\text { Técnicos" }\end{array}$ & $\begin{array}{l}\text { "presente em seus dispositivos de cor- } \\
\text { porativização e tecnificação do trabalho } \\
\text { político que restringem o sufrágio em } \\
\text { seu caráter participativo e eletivo: } \\
\text { "Conselho de Economia Nacional + } \\
\text { Departamento Administrativo + legisla- } \\
\text { ção trabalhista" }\end{array}$ \\
\hline $\begin{array}{l}\text { NACIONA- } \\
\text { LISMO }\end{array}$ & $\begin{array}{l}\text { * visível em sua política de naciona- } \\
\text { lização das atividades nacionais: } \\
\text { "propriedade de empresas } \\
\text { jornalísticas facultada apenas a } \\
\text { brasileiros"; } \\
\text { "prevê nacionalização de empresas } \\
\text { e ramos de produção"; } \\
\text { "formação de uma educação } \\
\text { eugênica que desenvolva espírito } \\
\text { brasileiro" }\end{array}$ & $\begin{array}{l}\text { * também visível em sua política de } \\
\text { nacionalização das atividades nacionais } \\
\text { e em suas medidas voltadas à corporati- } \\
\text { vização nacional: } \\
\text { "fundação de instituições voltadas a } \\
\text { organizar a juventude"; } \\
\text { "trabalho é um dever social necessário } \\
\text { aos interesses nacionais"; } \\
\text { * proibição de outros símbolos que não } \\
\text { os Nacionais }\end{array}$ \\
\hline
\end{tabular}




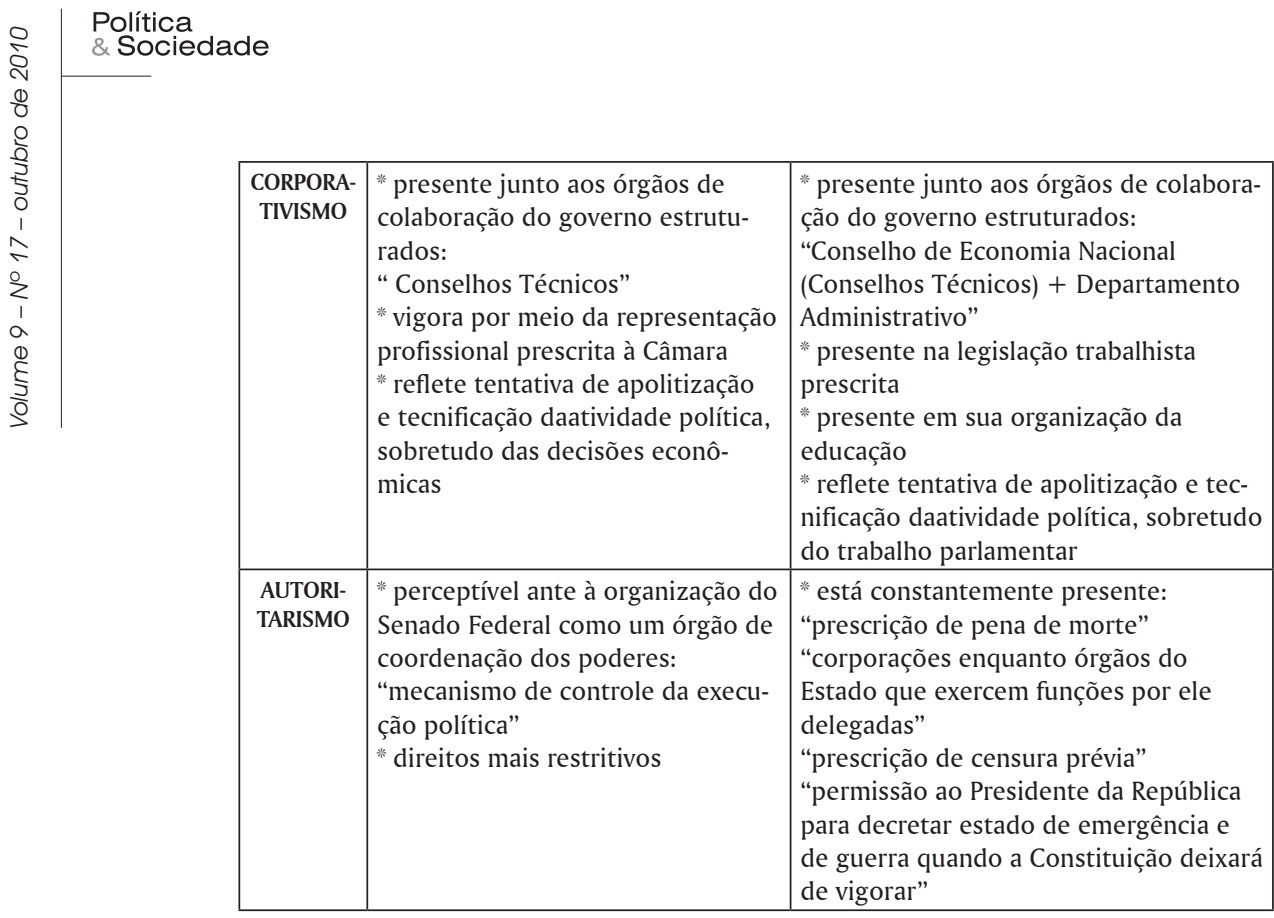

É nítido que ambas as Cartas inovaram ao seguirem um viés mais social e nacionalista em comparação ao texto de 1891 (discurso da crise no Quadro). Enquanto em 1891 a única preocupação foi assegurar o livre funcionamento da economia, estas duas Constituições adotaram o caminho contrário em sentido ao crescente abandono do liberalismo; primeiramente em suas formas econômicas (1934) e depois também em suas formas políticas (1937), (antiliberalismo no Quadro). Suas medidas mais centralizadoras visavam conter os efeitos danosos oriundos do ultra federalismo de 1891 e ao mesmo tempo promover condições ao desenvolvimento nacional. Para tal, estruturaram economias mais interventoras, sistemas educacionais civilizadores e políticas assistencialistas em aparente harmonia com os ideais do PAB. Contudo, essa nova postura resultou menos de uma direta incorporação desta ideologia, que do contexto mundial de falência do liberalismo. Como vimos, neste período sistemas semelhantes foram propostos e inaugurados por todo o mundo (HOBSBAWN, 2003). Até mesmo no Brasil esta receita já vinha há muito sendo discutida, embora só plenamente estruturada por esse conjunto de pensadores (SKIDMORE, 1975). Logo, o PAB não foi o único grupo a influenciá-las em sentido a supressão de seus excessos liberal e federalista. 
Ainda que esta primeira leitura aponte para a inexistência de um protagonismo político por parte desse grupo de intelectuais, a análise dos órgãos de colaboração vem confirmá-la (corporativismo no Quadro). As verdadeiras influências do PAB situam-se ao nível da formação de novos "instrumentos de poder" que não só auxiliavam na administração pública, mas antes refletiam uma tentativa de sua apolitização e corporativização de algumas atividades (elitismo no Quadro).Em diferentes graus, as Cartas de 1934 e 1937 caminharam em sentido à tecnificação do trabalho governamental e organização corporativa da sociedade. Suplantaram os princípios básicos do liberalismo - especialmente aqueles relacionados às causas da crise (sufrágio universal, federalismo) - em favor de elementos conhecidamente autoritários, deixando nítida a grande influência exercida por essas ideias (antiliberalismo no Quadro).

O texto de 1934 rebateu a inadequação do sistema representativo incorporando representantes profissionais à Câmara dos Deputados e instituindo o Senado Federal como órgão de controle da constitucionalidade. Ao mesmo tempo, criou conselhos técnicos para assessorar os ministérios e decisões parlamentares. Longe de responder às demandas sociais seguindo a lógica liberal da livre competição, suplantou estes princípios em favor da edificação de um Estado mais intervencionista e centralizado. Embora estes instrumentos não reproduzissem completamente a proposta de Estado do $\mathrm{PAB}$ - serviam antes ao controle do Executivo pelo Legislativo que o contrário - delinearam seus principais contornos.

Por sua vez, o texto de 1937 consolidou tal preferência estruturando mecanismos em nítida comunhão com o Estado do PAB, a começar pela quase que total centralização da atividade política no Executivo. Ao atribuir ao Presidente da República a faculdade de intervir livremente nos estados e expedir decretos-leis, assentou as bases à completa realização da proposta autoritária, quando o Executivo federal emerge como único elemento capaz e, por isso, necessário para conduzir a nação ao seu desenvolvimento. Ademais, a instauração do Departamento Administrativo e Conselho de Economia Nacional superaram as imprecisões da Carta de 1934, possibilitando a monopolização da atividade política (principalmente da atividade legislativa) pelo Executivo em colaboração com elites técnicas. Somados a uma 
visão autoritária das corporações, acenou não só à racionalização da atividade política, mas à corporativização da sociedade e, por isso, ao pleno domínio político do Presidente da República. Como o PAB, estruturou antes um regime autoritário que corporativo.

Deste modo, podemos afirmar que ambas as Constituições, em algum momento, recorreram aos princípios ideológicos do PAB. Como vemos no Quadro, se o texto de 1934 apenas se inspirou nesta ideologia, o texto de 1937 buscou concretizá-la em toda sua plenitude. Por mais que o próprio contexto histórico exigisse a construção de um Estado mais centralizado, nacionalista e democrático (no sentido da realização do interesse coletivo), em ambas as Cartas encontramos instrumentos e medidas claramente relacionadas à proposta de Estado do $\mathrm{PAB}$ - a modernização e o desenvolvimento impõem-se de cima para baixo; a participação é permitida, desde que dentro de canais bastante precisos; a atividade política é prescrita a elites técnicas. Em diferentes graus, cada uma dessas Cartas privilegiou a ordem à liberdade, apresentando o bem comum como a síntese do Estado. Isto explica suas semelhanças e aponta para imprecisão que é conceituar a Carta de 1934 como uma constituição tipicamente liberal, e a Carta de 1937 como a versão brasileira da Constituição polaca.

\section{Considerações finais}

Procuramos ao longo desta análise demonstrar que, na medida em que a Constituição reflete a emanação soberana da vontade do povo (os ideais em disputa) e o PAB foi a única corrente de pensamento do período capaz de estruturar uma ideologia de Estado, estavam postas as condições para o seu sucesso. Longe de as Constituições de 1934 e 1937 instituírem modelos de Estados opostos, ambas priorizaram o projeto nacionalista-autoritário quando de sua elaboração. Por mais que a Carta 1934 tratasse de uma Constituição elaborada democraticamente por meio de uma Assembléia Constituinte, suas características liberais resultaram antes da ausência de organização e poder dos autoritários para impor sua proposta, que da força das oligarquias nacionais. De certo modo, estas Cartas representam o próprio processo de maturação política e ideológica 
do grupo. Demonstram que a saída autoritária não se impôs do dia para a noite; de fato há muito vinha sendo gestada. Quando do Golpe de 1937 não só essa ideologia estava consolidada, como se encontrava materializada em uma Constituição.

Em resumo, embora aparentemente opostas, as Cartas de 1934 e 1937 bebem da mesma fonte: a ideologia de Estado do PAB. Isso evidencia que as Constituições não são meras legislações. Estão em íntima relação com os problemas e desafios postos por seu contexto histórico devendo, pois, serem estudadas em conjunto.

\section{Referências}

AMARAL, Azevedo. O Estado Autoritário e a Realidade Nacional. Rio de Janeiro: José Olympio, 1938.

BEIRED, J.L.B. Sob o Signo da Nova Ordem: intelectuais autoritários no Brasil e na Argentina (1914-1945). São Paulo: Loyola, 1999.

CAMARGO, A. (Org.). 1937: O Golpe Silencioso: as Origens da República Corporativa. Rio de Janeiro: Rio Fundo, 1989.

Constituição Brasileira de 1891. Disponível em: www2.camara.gov. br. Acesso em: 18 de abril de 2009.

Constituição Brasileira de 1934. Disponível em: www2.camara.gov. br. Acesso em: 18 de abril de 2009.

Constituição Brasileira de 1937. Disponível em: www2.camara.gov. br. Acesso em: 18 de abril de 2009.

Constituição Brasileira de 1946. Disponível em: www2.camara.gov. br. Acesso em: 18 de abril de 2009.

DINIZ, E. O Estado Novo: estrutura de poder e relações de classe. In: FAUSTO, B. (Org.). História Geral da Civilização Brasileira. Tomo II, v. 2. São Paulo: Difel, 1983.

DEL ROIO, Marcos. Os comunistas, a luta social e o marxismo (1920-1940). In: RIDENTI, M e REIS FILHO, D. A (org.). História do Marxismo no Brasil. v. 5. Campinas: Unicamp, 2002. 
FAUSTO, Boris. O pensamento nacionalista autoritário. Rio de Janeiro: Zahar, 2001.

. A Revolução de 1930. História e Historiografia. São Paulo: Companhia das Letras, 2002.

GOMES, A.M.C (Org.). Regionalismo e Centralização Política: Partidos e Constituinte nos anos 30. Rio de Janeiro: Nova Fronteira, 1980.

- Confrontos e Compromissos no processo de constitucionalização. In: FAUSTO, B. (Org.). História Geral da Civilização Brasileira. Tomo III, v. 3. Rio de Janeiro: Bertrand Brasil, 1990.

GOMES VIANNA, M.A. Revolucionários de 1935. Sonho e realidade. Tese (Faculdade de Filosofia Letras e Ciências Humanas), Universidade de São Paulo, 1990.

GOZZI, G. Estado Contemporâneo. In: BOBBIO, N., MATTEUCCI, N. e PASQUINO, G. Dicionário de Política. Brasília: UNB, 2004.

HOBSBAWM, E. A Era dos Extremos. O breve século XX (1914-1991). São Paulo: Companhia das Letras, 2003.

LAMOUNIER, B. Formação de um pensamento político autoritário na Primeira República. Uma interpretação. In: FAUSTO, B. (Org.). História Geral da Civilização Brasileira. Tomo III, v. 2. Rio de Janeiro: Difel, 1979.

LUKÁCS, G. Sociologia. In: NETTO, J.P. Coleção Grandes Cientistas Sociais. São Paulo: Ática, 1981.

MAIA, J.M.E. Idéias, Intelectuais, Textos e Contextos: Novamente a sociologia da cultura. BIB, no 6, p. 53-7, 2º semestre de 2006.

MANNHEIM, K. O Pensamento conservador. In: MARTINS, José de Souza. Introdução Crítica à sociologia rural. Hucitec: São Paulo, 1986.

MEDEIROS, J. Ideologia Autoritária no Brasil 1930-1945. Rio de Janeiro: FGV, 1978.

PÉCAUT, D. Os intelectuais e a política no Brasil. Entre o povo e a nação. São Paulo: Ática, 1990.

PIVA, L.G. Ladrilhadores e semeadores: a modernização no pensamento de Oliveira Vianna, Sérgio Buarque de Holanda, 
Azevedo Amaral e Nestor Duarte (1920-1940). São Paulo: Editora 34, 2000.

POLETTI, R. Constituições Brasileiras: 1934. Vol. III. Brasília: Senado Federal: 1999.

PORTO, W.C. Constituições Brasileiras: 1937. Vol. IV. Brasília: Senado Federal: 1999.

RODRIGUES, Leôncio Martins. Partidos e Sindicatos: escritos de sociologia política. São Paulo: Ática, 1990.

SILVA, H. 1934: A Constituinte. Rio de Janeiro: Civilização Brasileira, 1969.

. 1937: Todos os golpes se parecem. Rio de Janeiro: Civilização Brasileira, 1964.

SILVA, R. A Ideologia do Estado Autoritário no Brasil. Chapecó: Argos, 2004.

SKIDMORE, T. Brasil: De Getúlio a Castelo. Rio de Janeiro: Paz e Terra, 1975.

VIANNA, O. O idealismo da Constituição. São Paulo: Nacional, 1939.

1974a.

. Problemas de política objetiva. Rio de Janeiro: Record, . Instituições políticas brasileiras. Rio de Janeiro: Record, 1974b.

\section{Abstract}

The Constitutions of the Vargas Era, from the perspective of authoritarian thought of the 1930s

This paper looks at the 1934 and 1937 Constitutions from the perspective of the influence that Brazilian authoritarian thought - the only bearer of an effective State ideology during the period - had on them. Taking the general role that constitutions have had within modern societies into account (the building of a modern State based on the law and the expression of the people's will) and the specific one that was imposed by the national context (re-founding of the State), study of these two constitutions confirms the political protagonism that this current of thought took on, placing due attention on the ambiguities they contained. For 
these purposes, we have conducted a detailed analysis of both constitutions, while at the same time finding some parallels with the ideological themes and categories of the State that we have denominated as Brazilian Authoritarian Thought (Pensamento Autoritário Brasileiro (PAB) and with the Constitutions of 1891 and 1946 . We have, in this regard, sought to reveal the essence of these constitutions, analyzing them not as mere juridical texts but as legislation that must be understood within a specific political and cultural environment.

Keywords: Vargas Era, Brazilian authoritarian thought, Constitutions of the 1930s, authoritarian state. 